Sergio Rotasperti, Metaphors in Proverbs. Decoding the Language of Metaphor in the Book of Proverbs (Supplements to Vetus Testamentum 188; Leiden - Boston, MA: Brill 2021). Pp. XVIII+227. €109.00. ISBN 978-90-04-46410-0 (Hardback), 978-90-04-46605-0 (E-Book)

\title{
Mateusz Targoński
}

Pontifical Biblical Institute, Rome

targonski.mateusz@gmail.com

https://orcid.org/0000-0001-9523-9476

The Metaphors in Proverbs by Sergio Rotasperti is a revision of his doctoral thesis. The original dissertation was written in Italian and submitted in 2014 to the Pontifical Gregorian University in Rome. It has been already published "almost entirely" as «Sorgente di vita è la bocca del giusto». L'arte della metafora nel libro dei Proverbi (Collana Studi biblici 75; Bologna: Dehoniane 2016). The English version is shorter; in fact, when compared with the Italian edition, the omission of some paragraphs and bibliographic entries is conspicuous. The monograph comprises front matters, an introduction, five chapters, a conclusion, a bibliography and an index of modern authors (Aristotle included).

In the short (pp. 1-9) introduction, the author briefly presents the history of research on metaphor ("Metaphorical Language"), the poetic nature of Proverbs ("Metaphorical Language in Proverbs") and the method applied in the study ("Metaphorical Process"). The last one draws attention as Rotasperti explicitly states that he does "not apply any specific theory of metaphor" (p. 8), instead uses "- on a case-by-case basis - contemporary rereadings of Aristotle's thought on metaphor" (p. 9). This approach predictably leads to "a loose analysis of figurative language" noticed already by Walter J. Houston in his brief review of the Italian publication (Journal for the Study of the Old Testament 42/5 [2018] 103). The introduction also lacks an explicit statement regarding the goal of the study, which, instead, is found in the conclusion: "The aim of the present study has been twofold: firstly, to account for the phenomenon of the metaphor in Proverbs by means of lexical enquiry. The second, more complex aim was to launch a process of analysis of the metaphors by applying a suitable methodology" (p. 189). The author's actual methodology is presented below.

The first chapter (pp. 10-30) is introductory and covers three thematic areas. The first ("The Textual Fabric of the Metaphor") is an overview of the Book of Proverbs regarding the interconnection between orality and writing as well as its literary composition as a "collection of collections". The second ("Contextualizing Metaphors") describes the poetic nature of Proverbs, its cultural (Near Eastern and Hellenistic) and social ("family, court and scholastic") context, as well as the possible dating of the book. Finally ("Unveiling 
Metaphors"), Rotasperti provides a status quaestionis regarding metaphors in Proverbs and a survey of metaphorical elements in the book, conveniently organized into six categories: (1) the human body and its parts, (2) the animal world, (3) the urban environment, (4) natural elements, (5) preciousness and value and (6) utensils and objects of daily use. Interestingly, the fifth category disappears already in the summary of the first chapter (p. 30), while in the further study, only four first categories persist.

Four subsequent chapters are dedicated to the analysis of four thematic areas of metaphors in Proverbs. Their structure is identical, reflecting what the author considers "a suitable methodology" for the study. Each chapter begins with a survey of the respective lexical field (subchapter 1), organized in two stages: first (section 1.1), an extensive (although rarely comprehensive) catalogue of the relevant terms with their collocation in the structure of Proverbs and principal semantic associations; in the second (1.2), Rotasperti assesses the same terms more generally, especially in their relation to the human world and metaphoric force. The second subchapter is an analysis of five metaphors from the respective semantic field. The author is clear that his selection is subjective, although not random (p. 6). For each example, the entire verse is analysed. In many cases, the selection corresponds to the extension of the proverb under consideration, although often only a part of the proverb (or instruction) is studied in detail. Consequently, for any selected example, more than one metaphor is examined crossing the thematic boundaries proposed by Rotasperti. Thus, an index of the metaphorical terms would be more than welcome, as it is not self-explanatory that one interested in the raven and the eagle/vulture metaphor should look primarily into chapter 2 (dedicated to the human body), where Prov 30:17 is considered.

For each verse, Rotasperti applies a method he calls "metaphorical process" (the term seems to apply also to the metaphor understood as a process, as well as to the activity of the author of the metaphor). First, the Hebrew text along with an English translation and subdivision of the verse is presented. The proposed translation is not always apparent, and the author usually does not provide any explanation for it. Moreover, the translation (sometimes even the verse subdivisions) is not always maintained in the analysis that follows. In the second step, Rotasperti briefly argues for the metaphorical nature of the verse.

The third is gathered under the heading "The Text and Its Composition." It opens with a survey of text-critical issues, in particular concerning LXX. The author clearly states that "the preference is to preserve the reading of the Masoretic Text" (p. 84) and this part serves primarily to establish the literal meaning of the verse, often with syntactic and semantic considerations. It also explains the continuous swap between the terminology: this section is said to deal with "textual" or "philological" issues. Next, the structure of the verse is usually presented, although in some cases this part is simply omitted without any explicit rationale. Besides the semantic and syntactic aspects, sometimes the proposed structure is based also on the assonances in the Hebrew text. This section concludes with a very brief remark on the context of the verse. It is noteworthy that in the Italian version this part of the analysis is significantly more elaborate for each metaphor. 
In the fourth step ("Analysis of the Metaphorical Elements"), Rotasperti individuates and analyses "the lexical and syntagmatic elements that constitute the metaphorical expression" (pp. 7-8). The analysis is based mainly on the terms' occurrences in the Book of Proverbs and the entire Hebrew Bible (sometimes with a reference to the LXX correspondences). Second domain often considered is the real-life experience available in the biblical context. It covers vast range of subjects from the natural (especially animal) world to ancient technologies. Comprehensiveness is not possible in such a broad thematic range; nevertheless, Rotasperti provides valuable insight into the terms under consideration. The reader must remain careful, as some statements are apparently unfounded. It does not necessarily mean they are wrong; however, due to absent (or incorrect) references, verifying the author's claim is difficult. Moreover, there are several misinterpretations, both of the Hebrew source and the secondary literature.

The final step is called "Interpretation of the Metaphor" and "is intended to 'rework' all the elements previously examined" (p. 8). In fact, it is significantly ampler. Besides the creative reworking the earlier results, Rotasperti (in a somewhat haphazard manner, sadly) provides meaningful parallels from other sources, primarily Ben Sira and later Jewish tradition. Moreover, he very often refers to the Hebrew cantillation of the analysed verses and its impact on the interpretation of the text. The interpretations are meaningful, although sometimes far-fetched (once or twice, perhaps even difficult to accept). However, this freedom seems to be an intended feature of Rotasperti's method, as he concludes his introduction with Luis Alonso Schökel's warning: "Both the reader and the specialised exegete must be extremely careful not to let their own imagination be numbed when they read or study biblical poetry. What was written creatively must be received creatively" (Rotasperti's translation on p. 9; originally L. Alonso Schökel, Manuale di poetica ebraica [Biblioteca biblica 1; Brescia: Queriniana 1989] 130).

The methodology described above is applied in four main chapters (2-5) of the monograph. Chapter 2 (pp. 31-68) deals with the metaphors relating to the human body, including the hand, palm, foot, heart, mouth, lips, tongue, eye, pupil and eyelid. The verses analysed in the second stage are Prov 10:11; 15:4; 25:19; 27:9 and 30:17. Except for the third one, each can be readily appropriated to another category of metaphors. Noteworthy, the summary of this chapter contains not only a recapitulation of the earlier analysis but also some more general observations that concern the metaphors in Proverbs. Their influence on the general conclusions of the study is difficult to miss. In the third chapter (pp. 69-109), the urban and extra-urban elements surveyed encompass agglomerations (like city and town), structures (e.g., house and palace), urban details (tower, city square etc.) as well as various terms referring to roads. The verses selected for the analysis are Prov 10:29; 15:19; 18:19; $23: 27$ and 30:26. Chapter 4 (pp. 110-151) is entitled "In the World of Nature" and comprises various botanical terms, fruits of the earth, meteorological phenomena, as well as terms from the domain of geography, hydrography and geology. The classification is not always self-explanatory (e.g., "milk" in "The World of Botany"), although the coverage is vast and thus impressive. For a closer study, Prov 5:3; 11:22; 19:12; $26: 9$ and 26:23 have 
been chosen. In the final chapter (pp. 152-188), Rotasperti analyses the animal metaphors. The lexical field comprises "All Creatures Great and Small" and the second part focuses specifically on Prov 6:5; 15:17; 23:32; $26: 11$ and 28:15.

In the conclusion (pp. 189-197), the author states the twofold aim of the study and provides some more general assessments organized in two categories: "The Art of Metaphor in Proverbs" and "The Metaphor and Its Hermeneutical Implications." In the former, he observes linguistic, compositional and intertextual characteristics that became more evident as the result of the study. The latter category seems to be more problematic, as Rotasperti attempts to formulate more theoretical implications of his study along three axes: theological, epistemological and pedagogical. The lack of precise methodology (including, for example, the definitions of crucial terms like "metaphor" or "lexical element") and of comprehensiveness renders those conclusions prone to dismissal. The theological implication possibly arises from the choice of metaphors and comparative material; the epistemological broadly corresponds to the cognitive definition of the metaphor, and the pedagogical may be well taken as a premise rather than the conclusion of the entire study.

Significant timespan between the submission of the original thesis (2014) and the publication of the book raises a question of the book's up-to-dateness. The author seems to be aware of the issue as he updated the bibliography and consequently the content of the monograph. Sadly, only two publications (Wilma Mancuello González from 2018 and Isabel Cranz 2020) have been added to the bibliography, which does not reflect accurately scholars' work regarding the Book of Proverbs and the metaphor in the Bible in the relevant period. Apparently these two books did not significantly influence the content of the work as the index indicates only one reference of each author. In fact, the reference to I. Cranz, Royal Illness and Kingship Ideology in the Hebrew Bible (Society for Old Testament Studies Monograph Series; Cambridge: Cambridge University Press 2020) on page 50 (note 79) has only a loose association with the main text (typology of sickness in ancient Israel) and the preceding content of the note (Ben Sira's attention to medicine). This is surprising because the cited book has a specific excursus on Ben Sira's attitude to the physicians (pp. 152-162).

The great advantage of publication in English is the opportunity to bring Italian-language scholarship (not only of Rotasperti but also the numerous authors cited) to a broader audience. On the other hand, references to the Italian translations of the books written originally in English (of John M.G. Barclay, George B. Caird and Robert H. Robins) are a rather inconvenient reminder of the original language of the thesis. Less awkward, though still not the most practical, are references (that sometimes include retranslation of quotations) to Italian translations of books written in other languages where the English translations are easily available.

Without any doubt, the biggest advantage of the study is its vastness. First, the author performed an analysis of the entire Book of Proverbs, which overflows with metaphors. The list of the lexical terms surveyed is enormous. In the detailed study, he analysed not only the Hebrew text (the Masoretic but also from $4 \mathrm{QP} \operatorname{Prov}^{\mathrm{b}}$ wherever available and relevant) but 
also the Hebrew cantillation and virtually all relevant ancient versions: primarily LXX but also Peshitta, Targum and Vulgate. Second, the comparative material comprises not only the Book of Proverbs and the entire Hebrew Bible but also Near Eastern and Hellenistic context, Ben Sira (both Hebrew and Greek manuscripts) and later Jewish tradition. Finally, the vastness is perceptible not only in the range of the source material but also in the bibliography, which lists numerous studies in at least six modern languages.

On the other hand, its vastness is also one of the study's biggest disadvantages. It was impossible to render the study comprehensive. Numerous lexical terms had to be omitted, no lexical field could be analysed thoroughly, and the metaphors chosen for in-depth analysis do not represent all the collections in the book. Similarly, the comparative material is used inconsistently, often via secondary studies. Finally, in such a wide lexical field, it is not possible to maintain comprehensiveness regarding the studies that illuminate the real-life experiences relevant for the analysed metaphors. The incomprehensiveness together with the lack of precise methodology, requires caution if biased conclusions (especially due to overgeneralization) are to be avoided.

To sum up, the monograph is an inspiring study. Due to its structure, it is difficult to take it as a reference point in the general studies regarding the metaphor, the Book of Proverbs or both, although it surely can become an interesting conversational partner. On the other hand, it is a valuable resource regarding the particular metaphors and verses analysed indepth, when it provides not only an ample survey of the text and its semantic associations but also creative and thought-provoking interpretations. 
